\title{
Impact of tumor size on survival outcome of pancreatic carcinoma following pancreatic resection: A systematic review and meta-analysis
}

\author{
Anuj Shrestha' ${ }^{1,3}$, Attit Baskota ${ }^{4}, \mathrm{Fu}-\mathrm{Yu} \mathrm{Li}^{2}$, Wen-Jie $\mathrm{Ma}^{3}$, Qin Yang ${ }^{3}$, Hu-Hai Jie ${ }^{3}$, \\ Sunil Man Bijukchhe ${ }^{1}$ \\ ${ }^{1}$ Lecturer, Department of Surgery, Gandaki Medical College, ${ }^{2}$ Professor, Department of Biliary Surgery, West China \\ Hospital of Sichuan University, China, ${ }^{3}$ Post-graduate student, Department of Biliary Surgery, West China Hospital of \\ Sichuan University, China, ${ }^{4}$ Consultant, Department of Medicine, Kathmandu Model Hospital
}

\section{A B S T R A C T}

The aim of the study was to evaluate the influence of tumor size on long-term survival outcome of pancreatic tumors following pancreatic resection and the possibility of implementing another tumor size cut-off point in AJCC pancreatic tumor staging. Literature searches was conducted on electronic database to identify relevant studies on tumor size related survival outcome following pancreatic resection for pancreatic adenocarcinoma. Meta-analysis was done using the effect estimates and the use of $95 \%$ confidence intervals (Cls) was done to calculate the pooled risk estimates; heterogeneity among studies was examined using $\mathrm{I}^{2}$ statistic. Total of 18 trials (13 retrospective and 5 prospective studies) including 6230 elderly patients was included in this study. The pooled HR of the tumor size with $2 \mathrm{~cm}$ cut-off was 1.43 with $95 \% \mathrm{Cl}$ of [1.27-1.62], $\mathrm{I}^{2}=17 \%, p<0.00001$ and was statistically significant. Median survival for tumor size $<2,>2,<3,>3,<4$ and $>4$ were 41.02 months, 16.20 months, 19.41 months, 10.79 months, 24.2 months and 15.14 months respectively and the 1-, 3-, and 5-year survival rate decreased with increasing tumor diameter. Importantly, a total of four studies results indicated that 3-year survival rate and a total of five studies results indicated that 5-year survival rate had statistical significance with $3 \mathrm{~cm}$ cut-off. Tumor diameter of $2 \mathrm{~cm}$ seems to be a reasonable but relatively less comprehensive cut-off point. $3 \mathrm{~cm}$ cut-off maybe become a new potential tumor size cut-off point in addition to the current sole $2 \mathrm{~cm}$ cut-off point defining tumor stage.

Key words: Tumor size, Pancreatic cancer, Pancreaticoduodenectomy, Survival outcome

Access this article online

Website:

http://nepjol.info/index.php/AJMS

DOI: 10.3126/ajms.v9i1.18714

E-ISSN: 2091-0576

P-ISSN: 2467-9100

\section{INTRODUCTION}

Pancreatic cancer is a highly fatal disease. It is regarded as one of the leading cause of cancer death accounting for $4.8 \%$ and $5.5 \%$ of cancer death in men and women respectively. ${ }^{1,2}$ Prognosis in patient diagnosed with pancreatic cancer is very dismal and even after successful curative resection, the 5-year survival rate still remains as low as $5 \%-20 \%$ as reported by most of the literatures. ${ }^{3-5}$ Tremendous development of surgical and vascular techniques and imaging technology, resection of pancreatic cancer has increased significantly in recent years. However, due to rapid local lymphatic spread, vascular invasion or metastasis, approximately $80 \%$ of the pancreatic cancer patients are not eligible for surgical resection. ${ }^{6,7}$

Several factors have been noted to influence the survival following surgical resection of pancreatic carcinoma. Lymph node status, peri-neural/vascular invasion, tumor staging (TNM status), tumor type, resectability, comorbidity and patient age have all been reported to affect the outcome. ${ }^{8-12}$ However, tumor size has been considered 
to be a key prognostic feature and certainly have a great impact on survival outcome after surgical resection. In fact, the American Joint Committee on Cancer (AJCC) staging system for pancreatic cancer has clearly defined the difference between a T1 and T2 tumor solely by the size of the tumor $(\leq 2 \mathrm{~cm}$ vs. $>2 \mathrm{~cm}) .{ }^{13} \quad$ In AJCC TNM staging, tumor $(\mathrm{T})$ staging is not relatively comprehensive as it is solely differentiated by tumor diameter with $2 \mathrm{~cm}$ cut-off. Tumor diameter with $3 \mathrm{~cm}$ and $4 \mathrm{~cm}$ cut-offs are not specified in the staging and thus causing conflicts about selection of the tumor size cut-off in defining the tumor stage. Many studies have favored the AJCC tumor staging cut-off of $2 \mathrm{~cm},{ }^{14-16}$ whereas there are studies ${ }^{17-19}$ which reports the indication for reconsideration of the tumor stage cut-off, to provide more precise reference for staging and predicting survival outcome. Moreover, the impact of tumor size on survival outcome also remains controversial. Several studies ${ }^{10,17,20}$ have reported no influence of tumor size on long-term survival, while others ${ }^{9,14,21}$ have favored smaller tumor size to have better result than the larger tumors. An increased tumor mass could impact on the occurrence of metastatic lymph nodes, resection margins and finally, long-term survival. ${ }^{14}$ Although previous literatures have analyzed heterogeneous array of patient and tumor factors, few have specifically examined the prognostic effect of the tumor size. ${ }^{21}$ Therefore, the present study aimed to highlight following points: 1) to assess the influence of tumor size on survival outcome following pancreatic cancer, 2) to evaluate the accuracy and comprehensiveness of tumor size cut-off of $2 \mathrm{~cm}$ as suggested by current AJCC staging system, 3) to evaluate the possibility of implementing another tumor size cut-off using $3 \mathrm{~cm}$ or $4 \mathrm{~cm}$ so as to evaluate which accurate $T$ stage does tumor with $3 \mathrm{~cm}$ and $4 \mathrm{~cm}$ diameter belong to, and to predict its prognosis following surgery, 4) to provide a pivotal reference for new AJCC stage system and treatment for pancreatic cancer.

\section{MATERIAL AND METHODS}

\section{Search strategy and study identification}

Electronic databases were searched for studies and literatures in the PubMed MEDLINE, Ovid MEDLINE, EMBASE and Cochrane library from January 2000 to December 2016. Searching terms were used as "(Whipple procedure or Whipple surgery or Whipple operation or pancreaticoduodenectomy or pancreatectomy) AND (pancreatic tumor or pancreatic carcinoma or pancreatic malignancy or pancreatic neoplasm) AND (survival outcome or prognosis) AND (tumor size)" with restriction of English language but not to article type. The titles of the articles were reviewed and a reference check was performed to determine whether the article met the inclusion criteria.
The flow diagram of searching strategy is shown in Figure 1. A total of 515 articles and abstracts were identified by initial searches, of which 460 articles were excluded by manual screening of the titles, abstracts and animal experiments. An additional 29 papers were excluded after reading the full text. A total of 4 manuscripts were further added after manual reference search, therefore, leaving 30 articles for full publication review. Of these, 30 appropriate manuscripts, we found survival outcome was not compared as per the tumor size cut-off in 3 studies, ${ }^{22-24}$ tumor size was not differentiated in 5 studies $^{25-29}$ and outcomes of pancreatic adenocarcinoma was not differentiated with other pancreatic malignancies in 4 studies. ${ }^{8,30-32}$ Finally, 18 articles were included after reading the full papers (Table 1). ${ }^{4,15-19,33-44}$

\section{Inclusion and exclusion criteria}

Included studies should meet the following criteria: 1) Studies should be published in English language irrespective of research methods, 2) manuscripts containing data of pancreatic adenocarcinoma undergoing pancreatic resection, 3) manuscripts should contain major outcome determinants of long-term survival such as patient demographics, operative detail, tumor characteristics (tumor size, tumor differentiation), median survival rate, yearly survival rates, and/or effect estimates (HR) assessing the association of tumor size with its corresponding 95\% CI.

Studies that were conducted on animals, and with insufficient data were all excluded. When two studies were reported including same patients totally or partly by the same institution, the publication with more sample size was included. Studies which did not differentiated the outcome data of other pancreatic malignancies like neuroendocrine

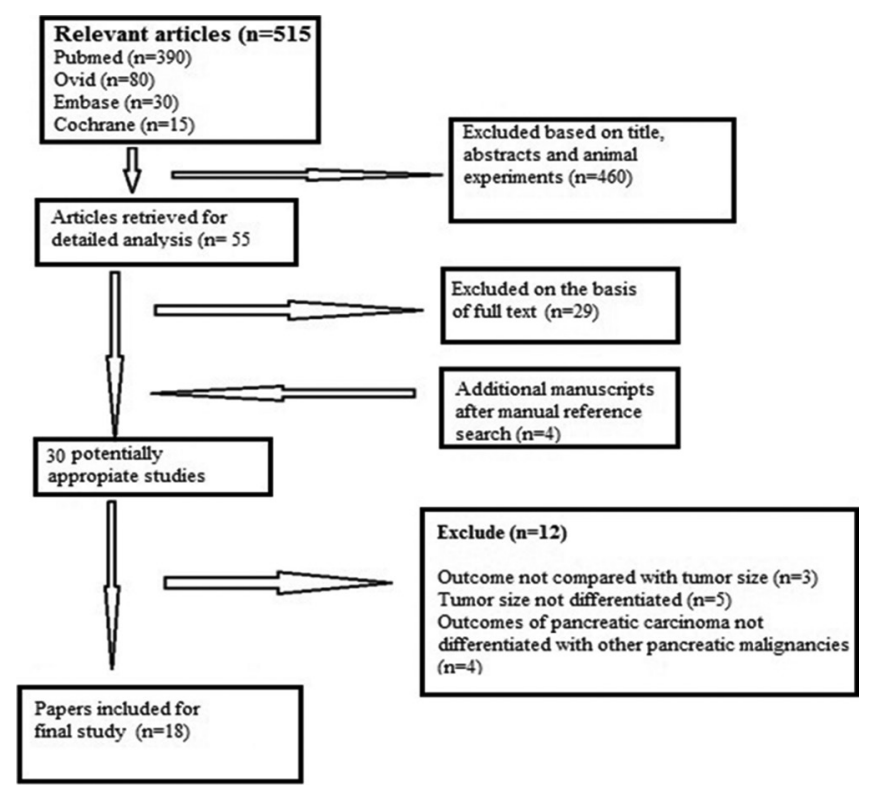

Figure 1: Flow chart of search identification process. 
Table 1: Baseline characteristics of included studies ( $\mathrm{N}-18)$

\begin{tabular}{|c|c|c|c|c|c|c|c|c|c|}
\hline Author & Year & Type of Study & M\% & $\begin{array}{c}\text { Sample } \\
\text { Size }(N) /(n)\end{array}$ & Intervention & Country & $\begin{array}{c}\text { Age (years) } \\
X / Y\end{array}$ & $\begin{array}{l}\text { Tumor } \\
\text { size }(\mathrm{cm})\end{array}$ & $\begin{array}{l}\text { Outcome } \\
\text { comparison }\end{array}$ \\
\hline${ }^{*}$ Sohn et al ${ }^{(19)}$ & 2000 & Retrospective & 54 & $593 / 616$ & $\begin{array}{l}\text { PD-526 } \\
\text { DP-52 } \\
\text { TP-38 }\end{array}$ & USA & $64.3 / 66$ & $<3 \geq 3$ & $a, c, d, e$ \\
\hline Meyer et al ${ }^{(15)}$ & 2000 & Retrospective & 59 & $86 / 113$ & $\begin{array}{l}\text { PD- } 105 \\
\text { DP- } 7 \\
\text { TP- } 1\end{array}$ & Germany & NA/64 & $\leq 2>2$ & $a, b, c, d$ \\
\hline $\begin{array}{l}{ }^{*} \text { Magistrelli } \\
\text { et al( }{ }^{(35)}\end{array}$ & 2000 & Retrospective & 60 & $73 / 73$ & $\begin{array}{l}\text { PD-45 } \\
\text { DP-10 } \\
\text { TP-18 }\end{array}$ & Italy & $60.9 / 62$ & $<3 \geq 3$ & $b, c, e$ \\
\hline $\begin{array}{l}\text { *Benassai } \\
\text { et al }{ }^{(18)}\end{array}$ & 2000 & Retrospective & 67 & $67 / 75$ & PD-75 & Italy & 67/NA & $<3 \geq 3$ & $c, d, e$ \\
\hline${ }^{*}$ Kedra et al ${ }^{(16)}$ & 2001 & Prospective & 54 & $136 / 212$ & $\begin{array}{l}\text { PD-98 } \\
\text { PPPD- } 50 \\
\text { TP- } 35 \\
\text { PP-29 }\end{array}$ & Poland & $63.1 / 65$ & $<2 \geq 2$ & $d, e$ \\
\hline${ }^{*}$ Takai et al ${ }^{(41)}$ & 2003 & Retrospective & 53 & $90 / 94$ & $\begin{array}{l}\text { PD-56 } \\
\text { TP-13 } \\
\text { DP-25 }\end{array}$ & Japan & NA/64 & $<3 \geq 3$ & $\begin{array}{l}a, b, c \\
d, e\end{array}$ \\
\hline Shoup et $\mathrm{al}^{(39)}$ & 2003 & Prospective & 47 & $57 / 57$ & $\mathrm{DP}$ & USA & NA/66 & $\leq 2>2$ & $d$ \\
\hline${ }^{*}$ Lim et al(40) & 2003 & Retrospective & 49 & $309 / 396$ & $\begin{array}{l}\text { PD-351 } \\
\text { PP-16 } \\
\text { TP-29 }\end{array}$ & USA & NA/72 & $\leq 2>2$ & $a, b, d, e$ \\
\hline Connor et $\mathrm{al}^{(38)}$ & 2004 & Prospective & 59 & $56 / 59$ & PD & UK & NA/65 & $\leq 2>2$ & $d$ \\
\hline Winter et $\mathrm{al}^{(4)}$ & 2006 & Retrospective & 54 & NA/1175 & $\begin{array}{l}\text { PD-834 } \\
\text { TP-79 } \\
\text { vessel } \\
\text { resection } 47\end{array}$ & USA & NA/66 & $<3 \geq 3$ & $a, c, d$ \\
\hline Shimada et al|(37) & 2006 & Retrospective & 71 & $88 / 88$ & $\begin{array}{l}\text { PD-76 } \\
\text { Appleby } \\
\text { operation-12 }\end{array}$ & Japan & $66 / 65$ & $<4 \geq 4$ & $a, b, c, d$ \\
\hline${ }^{*}$ Han et al(42) & 2006 & Retrospective & 70 & $117 / 123$ & $\begin{array}{l}\text { PD-98 } \\
\text { TP-2 DP-22 } \\
\text { Appleby } \\
\text { operation-1 }\end{array}$ & Korea & 57.9/NA & $\leq 3>3$ & $d, e$ \\
\hline${ }^{*}$ Pawlik et al(44) & 2007 & Prospective & 54 & $905 / 905$ & $\begin{array}{l}\text { PD-260 } \\
\text { PPPD- } 645\end{array}$ & USA & NA/66 & $\begin{array}{l}2 \mathrm{~cm} \\
\text { cut-off }\end{array}$ & $c, e$ \\
\hline${ }^{*}$ Li et al ${ }^{(43)}$ & 2008 & Retrospective & 61 & $134 / 134$ & $\begin{array}{l}\text { PD-105 } \\
\text { PPPD-29 }\end{array}$ & China & NA/57 & $\leq 2>2$ & $a, b, c, e$ \\
\hline *Ueda et al ${ }^{(36)}$ & 2009 & Retrospective & 57 & $135 / 140$ & $\begin{array}{l}\text { PD-54 } \\
\text { DP-35 TP-6 } \\
\text { PPPD-45 }\end{array}$ & Japan & $64.9 / 66$ & $<3 \geq 3$ & $\begin{array}{l}a, b, c \\
d, e\end{array}$ \\
\hline${ }^{*}$ De Jong et al ${ }^{(17)}$ & 2011 & Prospective & 53 & $1697 / 1697$ & $\begin{array}{l}\text { PD-502 } \\
\text { PPPD-1138 } \\
\text { TP-57 }\end{array}$ & USA & NA/67 & $\leq 2>2$ & $c, e$ \\
\hline Chiang et $\mathrm{al}^{(34)}$ & 2012 & Retrospective & 62 & $206 / 230$ & PD & Taiwan & 62.1/NA & $<3>3$ & $a, b, d$ \\
\hline $\begin{array}{l}{ }^{*} \text { Rohan et al }{ }^{(33)} \\
\text { Total }\end{array}$ & 2013 & Retrospective & $\begin{array}{l}81 \\
58\end{array}$ & $\begin{array}{c}32 / 43 \\
4781 / 6230\end{array}$ & $\begin{array}{l}\text { DP } \\
6045\end{array}$ & Taiwan & $\begin{array}{c}63.8 / 64.41 \\
63.39 / 65\end{array}$ & $\leq 4>4$ & $a, b, d, e$ \\
\hline
\end{tabular}

n- sample size undergoing intervention N-tumor size recorded sample size PD- Pancreaticoduodenectomy; DP- Distal pancreatectomy; TP-Total pancreatectomy; PP- Partial pancreatectomy; PPPD- Pylorus preserving pancreaticoduodenectomy X-mean age Y- median age a- 1-year survival; b-3-year survival; c- 5-year survival; d- median survival; e- hazard ratio with $95 \% \mathrm{Cl},(*)$ - Studies used for meta-analysis.

tumors, bile duct tumors and other ampullary carcinomas from the pancreatic adenocarcinoma were also excluded.

\section{Data extraction}

Two investigators (A.S. and A.B.) independently reviewed all the titles, abstracts, and manuscripts identified to determine if each study was eligible for inclusion in the study. Disagreement about eligibility were resolved by consensus with a third reviewer (L.F.Y.). All data were extracted using a standardized data extraction form. Relevant data were carefully extracted from each included studies which are as listed: first author, publication year, country, study design, sample size, intervention type, sex, age, recorded tumor size and comparable outcomes. Outcomes that were used to compare were median survival rate, 1 -year survival rate, 3 -year survival rate, 5-year survival rate and hazard ratio (HR) with its $95 \%$ CI.

The assessment of quality of all included studies for metaanalysis was performed based on the Newcastle-Ottawa 
scale by determining the selection of participants, the comparability and the outcome (Table 2 ). ${ }^{45}$

\section{Statistical analysis}

In systematic review, qualitative data assessing 3-year and 5-year survival ratio and tumor size with $3 \mathrm{~cm}$ cutoff were analyzed using chi square test. Furthermore, meta-analysis was performed using Review manager 5.3 software (Cochrane Library) for all statistical analysis. $\mathrm{P}$ value $\leq 0.05$ was considered statistically significant for all statistical analyses. Hazard ratio (HR) was considered as effect estimates and along with its corresponding 95\% CI was used to perform meta-analysis. Heterogeneity among studies was examined by $\mathrm{I}^{2}$ statistics. If chi-square test shows there is no significance of heterogeneity among the included studies $(\mathrm{p}>0.10)$, then fixed model was applied to calculate HR and its 95\% CI. In contrary, if there is significant heterogeneity among the included studies $(\mathrm{p} \leq 0.10)$, then random effects model as described by DerSimonian and Laird was performed to calculate the $\mathrm{HR}$ and its respective $95 \% \mathrm{CI}$.

Publication bias was assessed using the visual inspection of funnel plots, the Begg's rank correlation method and the Eggar weighted regression method $(\mathrm{P}<0.05$ was considered statistically significant publication bias). Fill and trim method were used if a publication bias existed.

\section{RESULTS}

The eighteen eligible manuscripts identified a total of 6230 patients in which pancreatic resection was performed for pancreatic adenocarcinoma with 4781 patients with recorded tumor size. These 4781 constitute the principal study population in this study. Included studies were mainly conducted in USA (6), Japan (3), Italy (2), Taiwan (2), UK (1), Poland (1), Germany (1), China (1) and Korea (1). Out of which thirteen retrospective and five prospective studies were included. The mean age in the 9 studies providing data on age was 63.3 years and the median age in the 15 studies providing data on age was 65 years. The median male \% (M \%) of the total study was $58 \%$. Table 1 shows the baseline characteristics of the final included studies. Finally, the quality assessment of the included studies for meta-analysis were done and shown in Table 2.

\section{SECTION 1}

\section{Systematic review}

Operation, intra-operative and post-operative data

Information on operative procedure was available for 6045 patients. Pancreaticoduodenectomy was carried out in $3504(57.96 \%)$ with pylorus preserving pancreaticoduodenectomy in 1907 (31.54\%) followed by total pancreatectomy in $278(4.60 \%)$, distal pancreatectomy in 251 (4.15\%), and partial pancreatectomy in 45 (0.74\%). Appleby operation with other vessel resection was performed in 60 patients $(0.99 \%)$. The median operating time for patient undergoing pancreatic resection for pancreatic adenocarcinoma was 6.3 hours as per 8 studies providing these data comprising of 4906 patients. ${ }^{4,17-19,34-36,44}$ Peri-operative mortality or mortality within 30 days of the date of operation was found to be $2.12 \%$ $(\mathrm{N}=117)$ in 13 studies providing this data with total of 5512 patients. ${ }^{4}, 16-19,33-36,41-44$

\section{Tumor size and survival}

Comparison of median survival with different tumor sizes is being graphically showed in Figure 2.

\begin{tabular}{|c|c|c|c|c|c|}
\hline \multirow[t]{2}{*}{ Studies } & \multicolumn{2}{|l|}{ Selection } & \multirow{2}{*}{$\begin{array}{l}\text { Comparability } \\
\text { Was the study } \\
\text { controlled for } \\
\text { confounders adequate }\end{array}$} & \multicolumn{2}{|l|}{ Outcome } \\
\hline & $\begin{array}{l}\text { Were } \\
\text { characteristics of } \\
\text { subjects clearly } \\
\text { described }\end{array}$ & $\begin{array}{l}\text { Were subjects } \\
\text { representative of the } \\
\text { entire population }\end{array}$ & & $\begin{array}{l}\text { Was the } \\
\text { ascertainment of } \\
\text { the outcome clearly } \\
\text { described }\end{array}$ & $\begin{array}{l}\text { Was the follow } \\
\text { up long enough }\end{array}$ \\
\hline Sohn 2000 & Yes & Yes & Yes & Yes & Yes \\
\hline $\begin{array}{l}\text { Benassai } \\
2000\end{array}$ & Yes & Yes & Yes & Yes & Yes \\
\hline Kedra 2001 & Yes & Yes & Yes & Yes & Yes \\
\hline Takai 2003 & Yes & Yes & Yes & Yes & Yes \\
\hline Lim 2003 & Yes & Yes & Yes & Yes & No \\
\hline Han 2006 & Yes & Yes & Yes & Yes & Yes \\
\hline Pawlik 2007 & Yes & Yes & Yes & Yes & Yes \\
\hline Ueda 2009 & Yes & Yes & Yes & Yes & Yes \\
\hline $\begin{array}{l}\text { De Jong } \\
2011\end{array}$ & Yes & Yes & Yes & Yes & Yes \\
\hline Rohan 2013 & Yes & Yes & Yes & Yes & Yes \\
\hline
\end{tabular}




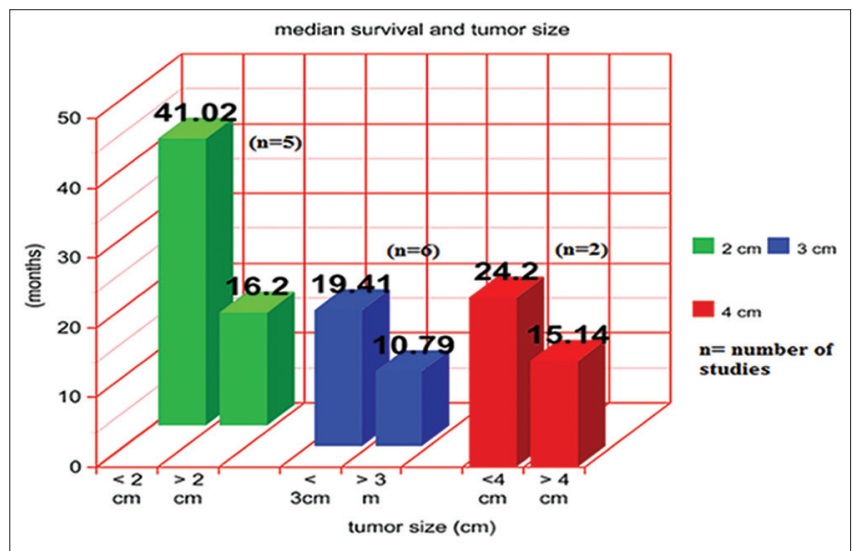

Figure 2: comparison of median survival month with (a) respective tumor size; (b) respective lymph node status, tumor grade and tumor resection margin.

\section{Survival outcome $<2 \mathrm{~cm}$ vs. $>2 \mathrm{~cm}$}

6 studies ${ }^{15,16,38-40,43}$ compared survival outcome between tumor size $<2 \mathrm{~cm}$ and $>2 \mathrm{~cm}$. Out of which 5 studies ${ }^{15,16,38-40}$ including 644 patients provided data on median survival. Median survival of 41.02 months was seen in tumor size $<2 \mathrm{~cm}$ whereas, tumors $>2 \mathrm{~cm}$ had median survival of 16.20 months. 3 studies ${ }^{15,40,43}$ including 529 patients compared data on 1-year and 3-year survival rate. 1-year and 3 -year survival rate of $79.36 \%$ and $49.38 \%$ was seen with tumor $<2 \mathrm{~cm}$ respectively whereas, 1 -year and 3 -year survival rate of $56.40 \%$ and $24.89 \%$ was seen with tumors $>2 \mathrm{~cm}$ respectively. Finally, 2 studies ${ }^{15,43}$ including 220 patients provided data on 5 -year survival rates. Tumors $<2 \mathrm{~cm}$ had 5 -year survival rate of $41.68 \%$ whereas, tumors $>2 \mathrm{~cm}$ had a low survival rate of $12.10 \%$.

Survival outcome $<3 \mathrm{~cm}$ vs. $>3 \mathrm{~cm}$

Seven studies ${ }^{18,19,34-36,41,42}$ compared survival outcome between tumor size $<3 \mathrm{~cm}$ and $>3 \mathrm{~cm}$. 6 studies ${ }^{18,19,34,36,41,42}$ including 1208 patients provided data on median survival. Tumors $<3 \mathrm{~cm}$ had a median survival of 19.41 months whereas, tumors $>3 \mathrm{~cm}$ had a median survival of 10.79 months. Similarly, 4 studies ${ }^{19,34,36,41}$ with a total of 1024 patients tallied data of 1-year survival rates. One year survival rate of $61.80 \%$ and $45.69 \%$ was seen with tumor size $<3 \mathrm{~cm}$ and $>3 \mathrm{~cm}$ respectively. Likewise, 4 studies $^{34-36,41}$ including 504 patients compared data of 3 -year survival rates. Three year survival rate of $25.6 \%$ and $14.36 \%$ was seen with tumor size $<3 \mathrm{~cm}$ and $>3 \mathrm{~cm}$ respectively and the result being statistically significant $(P<0.01)$ (Table 3). Finally, a total of 5 studies ${ }^{18,19,35,36,41}$ with 958 patients provided data on 5 -year survival rates. 5-year survival rate of $23.72 \%$ and $9.70 \%$ was seen with tumor size $<3 \mathrm{~cm}$ and $>3 \mathrm{~cm}$ respectively and the result being statistically significant $(P<0.001)$ (Table 3$)$.

Survival outcome $<4 \mathrm{~cm}$ vs. $>4 \mathrm{~cm}$

\begin{tabular}{|c|c|c|c|}
\hline \multirow[t]{2}{*}{ Studies } & \multicolumn{2}{|c|}{$\begin{array}{l}\text { 3-year Survival } \\
\text { ratio }(\mathrm{n} / \mathrm{N})\end{array}$} & \multirow[t]{2}{*}{$P$ value } \\
\hline & $<3 \mathrm{~cm}$ & $>3 \mathrm{~cm}$ & \\
\hline Chiang et al & $11 / 90$ & $17 / 116$ & NS $(P=0.613)$ \\
\hline Ueda et al & $19 / 49$ & $9 / 86$ & $P<0.001(P=0.000)$ \\
\hline Magistrelli et al & $12 / 42$ & $7 / 31$ & $\mathrm{NS}(\mathrm{P}=0.564)$ \\
\hline Takai et al & $12 / 33$ & $8 / 57$ & $P<0.05(P=0.014)$ \\
\hline Total & $54 / 214$ & $41 / 290$ & $P<0.01(P=0.002)$ \\
\hline \multirow[t]{2}{*}{ Studies } & \multicolumn{2}{|c|}{$\begin{array}{l}5 \text {-year Survival } \\
\text { ratio }(\mathrm{n} / \mathrm{N})\end{array}$} & $P$ value \\
\hline & $<3 \mathrm{~cm}$ & $>3 \mathrm{~cm}$ & \\
\hline Benassai et al & $11 / 33$ & $3 / 34$ & $P<0.05(P=0.014)$ \\
\hline Ueda et al & $13 / 49$ & $4 / 86$ & $P<0.001(P=0.000)$ \\
\hline Sohn et al & $59 / 268$ & $39 / 325$ & $P<0.01(P=0.001)$ \\
\hline Magistrelli et al & $9 / 42$ & $2 / 31$ & NS $(P=0.021)$ \\
\hline Takai et al & $9 / 33$ & $4 / 57$ & $P<0.05(P=0.021)$ \\
\hline Total & $101 / 425$ & $52 / 533$ & $P<0.001(P=0.000)$ \\
\hline
\end{tabular}

Only 2 studies ${ }^{33,37}$ compared survival outcome between tumor size $<4 \mathrm{~cm}$ and $>4 \mathrm{~cm}$. These 2 studies comprising 120 patients provided data on median survival, 1-, and 3 -year survival rates. Tumors $<4 \mathrm{~cm}$ had a median survival of 24.2 months and tumors $>4 \mathrm{~cm}$ had a median survival of 15.14 months. As per these 2 studies, 1 - and 3-year survival rates of $81.50 \%$ and $40.90 \%$ was seen with tumor size $<4 \mathrm{~cm}$ respectively. In contrast, 1 - and 3-year survival of $63.77 \%$ and $21.74 \%$ was seen with tumor size $>4 \mathrm{~cm}$ respectively.

\section{SECTION 2}

\section{Meta-analysis}

\section{Publication bias}

The funnel plot of studies included in tumor size with $2 \mathrm{~cm}$ cut-off seemed symmetrical, and no significant evidence of publication bias was seen as indicated by Begg's test and Egger's test (Begg's Test $P=0.086$; Egger's Test $P=0.057$ ). However, for the studies included in the tumor size with $3 \mathrm{~cm}$ cut-off, significant publication bias was seen (Begg's Test $P=0.024$; Egger's Test $P=0.013)$. The funnel plot showed asymmetry, so trim and fill method was used and the modified funnel plot after adding negative artificial data showed no asymmetry. The pooled result after the meta-trim method was summary $H R=1.352$ with $95 \%$ CI of $[0.860-2.126]$.

\section{Tumor size and survival outcome}

\section{$2 \mathrm{~cm}$ cut-off point and survival outcome}

The effect estimates along with its 95\% CI of original studies were extracted and standard errors (SE) for 
respective effect estimates were calculated for the metaanalysis. 5 studies $^{16,17,40,43,44}$ which provided the effect estimate assessing the tumor size with $2 \mathrm{~cm}$ cut-off point. The combined HR of the tumor size with $2 \mathrm{~cm}$ cut-off was 1.43 with $95 \%$ CI of [1.27-1.62], $\mathrm{I}^{2}=17 \%, p<0.00001$ and the result was statistically significant. As no heterogeneity among studies was seen $(p=0.31)$, fixed effect was used. (Figure 3 a)

\section{$3 \mathrm{~cm}$ cut-off point and survival outcome}

Similarly, 6 studies $^{18,19,35,36,41,42}$ were reported to provide data on effect estimate assessing tumor size with $3 \mathrm{~cm}$ cut-off. The combined HR of the tumor size with $3 \mathrm{~cm}$ cut-off was 1.35 with $95 \%$ CI of [0.86-2.13], $\mathrm{I}^{2}=85 \%$, $p=0.19$ ( $p$-value not significant). Random effect was applied, as heterogeneity among studies was seen $(\phi<0.00001)$. (Figure 3 b)

\section{$4 \mathrm{~cm}$ cut-off point and survival outcome}

Only one study ${ }^{(33)}$ compared survival with tumor size cutoff point $4 \mathrm{~cm}$. The tumor size more than $4 \mathrm{~cm}$ has HR of 2.96 with $95 \%$ CI of [1.28-6.82], $p=0.01$. As only one study was included, heterogeneity couldnot be calculated. (Figure $3 \mathrm{c}$ )

\section{Heterogeneity}

Tumor size cut-off $2 \mathrm{~cm}$ had no heterogeneity among studies $\left(\mathrm{I}^{2}=17 \%, p=0.31\right)$. However, for tumor size cut-off $3 \mathrm{~cm}$, moderate heterogeneity existed among studies $\left(\mathrm{I}^{2}=85 \%\right.$, $p<0.00001)$. Therefore, a sensitivity analysis was done by omitting 1 study at a time and the pooled HR was calculated for the remaining studies to identify the potential source of heterogeneity between studies. Sensitivity analysis by omitting Sohn $2000^{(19)}$, heterogeneity was partly attenuated with summary HR of 1.56 with a $95 \%$ CI of [1.00-2.45], $\mathrm{I}^{2}=$ $75 \%, p=0.003$ but publication bias was still present.

Stratified analysis was also done to identify the potential sources of heterogeneity that existed among studies. Heterogeneity was completely eliminated when studies were stratified accordingly as studies conducted in Asia $\left(\mathrm{I}^{2}=0 \%, p=0.67\right)$, studies with no peri-operative mortality $\left(\mathrm{I}^{2}=0 \%, p=0.64\right)$ and studies conducted after the year 2000 $\left(\mathrm{I}^{2}=0 \%, p=0.67\right)$.

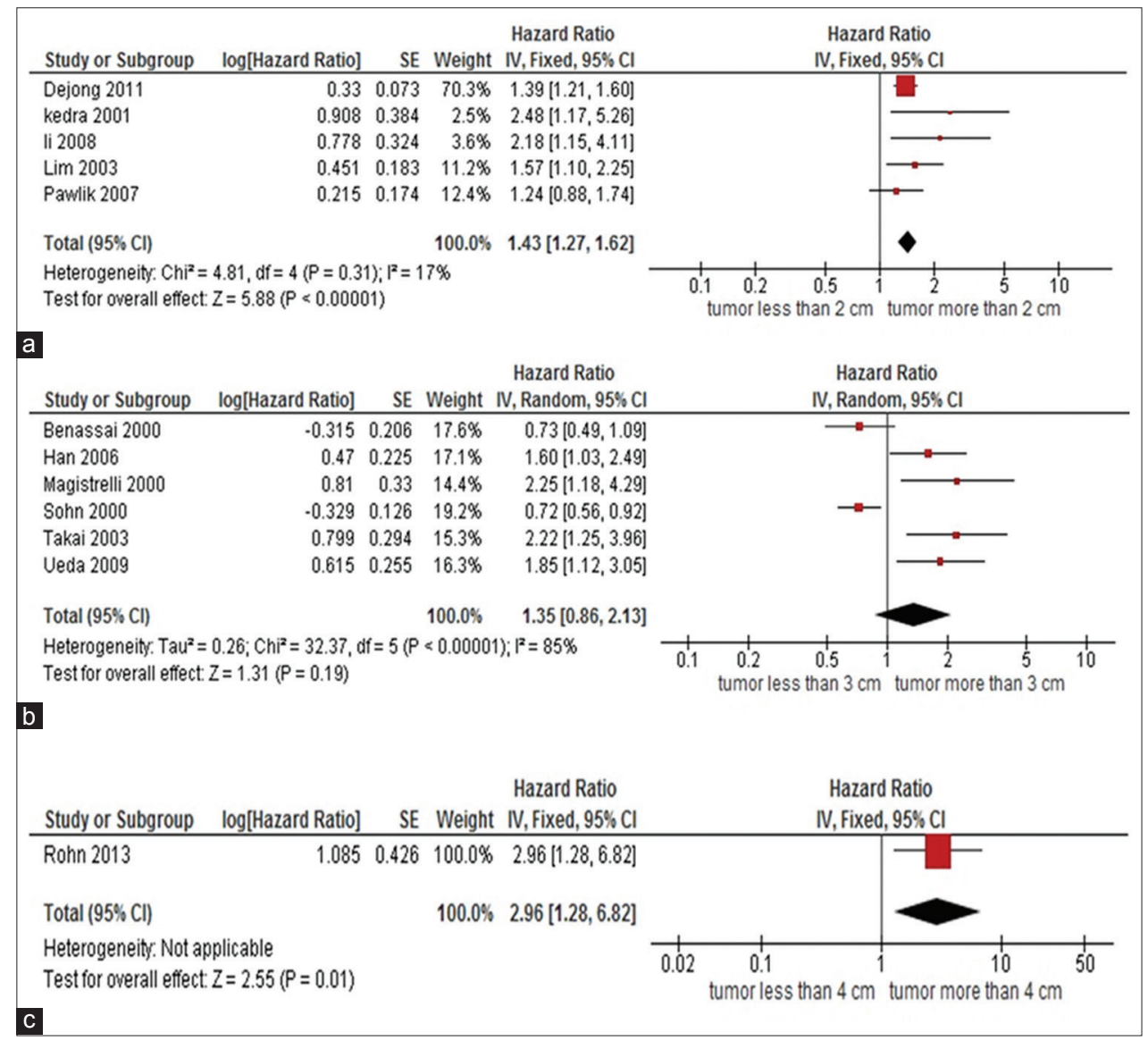

Figure 3: Meta-analysis of survival outcome and tumor size cut-off. Effect estimate (hazard ratio; 95\% Cl). Pooled HR is shown as diamond that spans the $95 \% \mathrm{Cl}$. (a) Forest plot showing effect estimates of each study and the pooled hazard ratio comparing the $2 \mathrm{~cm}$ tumor size cut-off point. (b) Forest plot showing effect estimates of each study and the pooled hazard ratio comparing the $3 \mathrm{~cm}$ tumor size cut-off point. (c) Forest plot showing effect estimates of each study and the pooled hazard ratio comparing the $4 \mathrm{~cm}$ tumor size cut-off point. 


\section{DISCUSSION}

American Joint Committee on Cancer (AJCC) staging system have been validated to predict the outcome of pancreatic cancer after pancreatic resection. ${ }^{46}$ However, AJCC tumor (T) staging is not relatively comprehensive as it is solely differentiated by tumor size with $2 \mathrm{~cm}$ cut-off. Tumor size with $3 \mathrm{~cm}$ and $4 \mathrm{~cm}$ cut-offs are not specified in the staging and thus causing conflicts about selection of the tumor size cut-off in defining the tumor stage. ${ }^{17,47,48}$ Thus, many studies suggest that $2 \mathrm{~cm}$ as cut-off point is not relatively comprehensive and warrants further researches on re-defining or suggesting multiple cut-off points i: e $2 \mathrm{~cm}, 3 \mathrm{~cm}$ or $4 \mathrm{~cm}$ in order to provide a more comprehensive guideline which accurately explains which tumor stage does tumors with $3 \mathrm{~cm}$ and $4 \mathrm{~cm}$ belong to and to plan treatment protocol in order to predict the survival outcome following surgery..$^{17,48-50}$ Tumor size is undoubtedly an important prognosticator for pancreatic tumor following pancreatic resection. ${ }^{14,49}$ However, the topic of debate is in choosing the right cut-off point for tumor diameter and many studies have already assessed and the most reported size cut-offs ranged from $2 \mathrm{~cm}$ to $3 \mathrm{~cm} \cdot{ }^{10,17,51-54}$ In our present study, the greatest impact of tumor size was seen on tumors below and above $2 \mathrm{~cm}$ with median survival of 41.02 months vs. 16.20 months respectively. However, for the larger tumor size the results is found to be less appealing, may be due to lesser number of studies and trials as in the present study we were able to include only 2 studies reporting survival outcome of tumors less or more than $4 \mathrm{~cm} .^{33,37}$

Various published reports supported the fact that smaller tumors have comparatively better survival outcome than larger tumors and the cut-off points ranged from $2 \mathrm{~cm}$ to $3 \mathrm{~cm} .{ }^{17,49,51-53}$ Yeo et al. ${ }^{9}$ reported a 5-year survival of $28 \%$ for tumor size less than $3 \mathrm{~cm}$ and $15 \%$ for tumor size more than $3 \mathrm{~cm}$. Similarly, Petermann et a ${ }^{14}$ reported a median survival of 40.8 months and 15.6 months for tumors less than $2 \mathrm{~cm}$ and more than $2 \mathrm{~cm}$ respectively, which was very similar to our result. Our systematic review analysis of tumor size and survival outcome, tumor size less than $2 \mathrm{~cm}$ had a median survival, 1-, 3-, and 5-year survival of 41.02 months, $79.36 \%, 49.38 \%$ and $41.68 \%$ respectively. In contrast, tumor size more than $2 \mathrm{~cm}$ had a median survival, 1 -, 3-, and 5-year survival of 16.20 months, $56.4 \%, 24.89 \%$ and $12.10 \%$ respectively. Similarly, tumor size less than $3 \mathrm{~cm}$ had a median survival, 1-, 3-, and 5-year survival of 19.41 months, $61.8 \%, 25.6 \%$, and $23.72 \%$ respectively. Whereas, tumor size more than $3 \mathrm{~cm}$ had a median survival, 1 -, 3-, and 5-year survival of 10.79 months, $45.69 \%, 14.36 \%$ and $9.70 \%$ respectively. The 3 -year and 5 -year survival rate difference between tumor size $<3 \mathrm{~cm}$ and $>3 \mathrm{~cm}$ was statistically significant. Similar to our result, many studies $9,26,55,56$ reported that survival time have statistical significance with $3 \mathrm{~cm}$ cut-off, which indicate the $3 \mathrm{~cm}$ cut-off maybe become another new potential tumor size cut-off in the new $\mathrm{T}$ stage of pancreatic cancer in addition to the current sole $2 \mathrm{~cm}$ cut-off point defining tumor stage proposed by AJCC.

Subsequently, our meta-analysis showed that the combined HR of the tumor size with $2 \mathrm{~cm}$ cut-off was 1.43 with $95 \%$ CI of [1.27-1.62], $\mathrm{I}^{2}=17 \%$, and the result being statistically significant $(p<0.00001)$. Similarly, the combined HR of the tumor size with $3 \mathrm{~cm}$ cut-off was 1.35 with $95 \%$ CI of [0.86-2.13], $\mathrm{I}^{2}=85 \%, p=0.19$. The combined pooled HR of tumor size with $3 \mathrm{~cm}$ cut-off did suggest that tumor size more than $3 \mathrm{~cm}$ have bad prognosis in comparison to tumor size less than $3 \mathrm{~cm}$ but the final result was not statistically significant and the study had moderate amount of heterogeneity. Stratified analysis was done to find the source of heterogeneity. Studies when stratified accordingly as studies conducted in Asia, studies with no peri-operative mortality and studies conducted after the year 2000 AD, all demonstrated statistically significant result with completely attenuated heterogeneity. Although the variables used for sub-group analysis have least clinical significance, but the result demonstrated were statistically significant. Therefore, concluding that further randomized controlled trials (RCTs) and retrospective studies with various tumor size cut-offs are required in future to obtain a clinically and statistically significant result. AJCC classification of tumor size via $2 \mathrm{~cm}$ cut-off point is supported by various studies ${ }^{14,23,32,46,57,58}$ but also debated by number of studies as the cut-off point being not relatively comprehensive. ${ }^{17,39,47,48}$ Currently, there are not adequate literatures that compares survival outcomes with respective tumor size cut-offs like $2 \mathrm{~cm}$, $3 \mathrm{~cm}$ and $4 \mathrm{~cm}$. If these sort of studies with more precise sub-division are available in the future than, the tumor stage classified by AJCC can be argued to be changed to a more feasible and effective point that can act as a pivotal reference to new AJCC staging system and thus help to decide in further planning the treatment protocol of the patient and predict survival outcome following surgery. However, for the time being, as per our study result the tumor size less than $2 \mathrm{~cm}$ seems to have a great impact on survival after pancreaticoduodenectomy.

Researches have reported that tumor size and prognosis are inversely proportionate. ${ }^{9,49,50}$ Our study showed that patient with tumor size $>2 \mathrm{~cm}$ had a reduced survival rate. There are many points that supports larger tumor size have negative impact on survival. Large tumors are believed to be more often associated with poor prognostic factors like micro-metastases, lymph vessel, perineural and loose connective tissue invasion due to their long term presence. ${ }^{14,17,21}$ Likewise, larger tumor size was noted to 
have longer operating times, more intra-operative blood loss, requirement of packed red blood cell transfusion and more importantly, larger tumor size are relatively harder to achieve microscopically negative tumor resection margin." ${ }^{17}$ Yamaguchi et $\mathrm{al}^{21}$ reported that tumors measuring less than $2 \mathrm{~cm}$ were less likely to be associated with nodal metastasis and were better differentiated than larger tumors. Similarly, Petermann et a $1^{14}$ reported that the risk for metastatic lymph nodes and positive resection margin was $40 \%$ and $7 \%$ respectively in the case of tumor size less than $2 \mathrm{~cm}$ compared with $>80 \%$ and $>30 \%$ for larger tumors respectively.

With tremendous development of imaging studies, it is now possible to detect smaller tumors early but the pancreatic carcinoma's long-term survival outcome in comparison to other abdominal malignancies is still far from satisfactory. This can be reasoned as many pancreatic cancer patients remain asymptomatic until late and CT or MRI findings of very small tumors are often understated and easily overlooked. ${ }^{59}$ Thus, most of the patients are easily misdiagnosed and usually present late with the classical symptoms and larger tumor diameters. Therefore, a more practical and innovative approach towards early detection of pancreatic cancer is a necessity and may be the only approach to improve the current long term effectiveness of pancreatic carcinoma. In addition, radiological finding of early pancreatic cancer is not adequate to support for performing major surgery like PD, particularly if patient is asymptomatic. ${ }^{60,61}$ Gangi et al ${ }^{59}$ described the presence of pancreatic ductal dilation without any identifiable mass several months before final diagnosis of pancreatic cancer. Endoscopic ultrasound-guided FNA (EUS-FNA) is believed to provide cytological diagnosis with specificity of around $100 \%{ }^{24,60,62}$ Therefore, usage of EUS-FNA whenever necessary can achieve early diagnosis and can act as a sound basis for prompt treatment and definitive management of pancreatic cancer, including PD. Other factor that is regarded highly in terms of survival outcome is tumor resection margin. ${ }^{9,18}$ Larger tumors are relatively harder to achieve R0 resection. Preoperative use of neo-adjuvant therapy is being increasingly common. Mainly because neo-adjuvant therapy is believed to be able to downstage locally advanced tumors and achieve an enhanced resection rate. ${ }^{63,64}$ However studies do not support or advocate routine use of preoperative neoadjuvant therapy for pancreatic cancer. ${ }^{24}$

\section{Limitations}

Present studies certainly have some limitation. First the tumor sizes provided by various studies have not stated if the tumor size is the post-operative pathological assessment or the pre-operative imaging assessment. However, the main purpose of the present study was to evaluate the impact of tumor size as predicted by AJCC. Another limitation of this study was the inclusion of pancreatic body or tail carcinoma due to limited number of studies performed exclusively on pancreatic adenocarcinoma of the head and uncinate process. However, the current study has solely included pancreatic adenocarcinoma only excluding all other neuroendocrine tumors and other pancreatic malignancies which have higher survival rates although with larger tumor diameters.

\section{CONCLUSION}

Surgical resection is the only possibility for chance of curative treatment available for pancreatic cancers. Improvement in imaging studies, surgical techniques as well as better understanding of its pathogenesis, availability of molecular markers and ability to perform biopsy of suspicious lesion with EUS-FNA safely all help to succeed in better and early diagnosis of the disease with better survival outcome.

Our study suggest tumor size less than $2 \mathrm{~cm}$ have significant impact on survival outcome and cancers with smaller tumor diameter is highly likely to be associated with negative lymph node metastasis and negative tumor resection margin. However, the $2 \mathrm{~cm}$ cut-off as suggested by AJCC is not relatively comprehensive and is thus debatable. Although our result supports the AJCC staging of pancreatic carcinoma, further evidence based trials, and further more studies discussing tumor with $3 \mathrm{~cm}$ and $4 \mathrm{~cm}$ cut-offs are required to provide the basis for formation of a comprehensive guideline which can settle the ongoing disputes regarding tumor staging suggested by AJCC and also to confirm that tumor size selection is one of the important prognostic factor that influence survival following pancreatic resection. Furthermore, the $3 \mathrm{~cm}$ cut-off maybe become another new potential tumor size cut-off point in new T stage of pancreatic cancer in addition to the current sole $2 \mathrm{~cm}$ cutoff point defining tumor stage.

\section{REFERENCES}

1. Edwards BK, Howe HL, Ries LA, Thun MJ, Rosenberg HM, Yancik R, et al. Annual report to the nation on the status of cancer, 1973-1999, featuring implications of age and aging on US cancer burden. Cancer 2002; 94(10):2766-2792.

2. Jemal A, Murray T, Ward E, Samuels A, Tiwari RC, Ghafoor A, et al. Cancer statistics, 2005. CA: a cancer journal for clinicians 2005;55(1):10-30.

3. House MG, Gönen M, Jarnagin WR, D'Angelica M, DeMatteo RP, Fong $Y$, et al. Prognostic significance of pathologic nodal status in patients with resected pancreatic cancer. Journal of Gastrointestinal Surgery 2007;11(11):1549-1555.

4. Winter JM, Cameron JL, Campbell KA, Arnold MA, Chang DC, Coleman J, et al. 1423 pancreaticoduodenectomies for pancreatic cancer: a single-institution experience. Journal of 
Gastrointestinal Surgery 2006;10(9):1199-1211.

5. Richter A, Niedergethmann M, Sturm JW, Lorenz D, Post S and Trede M. Long-term results of partial pancreaticoduodenectomy for ductal adenocarcinoma of the pancreatic head: 25-year experience. World journal of surgery 2003;27(3):324-329.

6. Sener SF, Fremgen A, Menck HR and Winchester DP. Pancreatic cancer: a report of treatment and survival trends for 100,313 patients diagnosed from 1985-1995, using the National Cancer Database. J Am Coll Surg 1999;189(1):1-7.

7. Tan HP, Smith J and Garberoglio CA. Pancreatic adenocarcinoma: an update. J Am Coll Surg 1996;183(2):164.

8. Bouvet M, Gamagami RA, Gilpin EA, Romeo O, Sasson A, Easter DW, et al. Factors influencing survival after resection for periampullary neoplasms. The American Journal of Surgery 2000;180(1):13-17.

9. Yeo CJ, Cameron JL, Lillemoe KD, Sitzmann JV, Hruban RH, Goodman SN, et al. Pancreaticoduodenectomy for cancer of the head of the pancreas. 201 patients. Annals of Surgery 1995; 221(6):721.

10. Garcea G, Dennison AR, Pattenden CJ, Neal CP, Sutton CD and Berry DP. Survival following curative resection for pancreatic ductal adenocarcinoma. A systematic review of the literature. Jop 2008;9(2):99-132.

11. Samra JS, Gananadha S and Hugh TJ. Surgical management of carcinoma of the head of pancreas: extended lymphadenectomy or modified en bloc resection? ANZ journal of surgery 2008;78(4):228-236.

12. Kennedy EP and Yeo CJ. Pancreaticoduodenectomy with extended retroperitoneal lymphadenectomy for periampullary adenocarcinoma. Surgical oncology clinics of North America 2007;16(1):157-176.

13. Edge SB, Byrd DR, Compton CC, Fritz AG, Greene FL and Trotti A. AJCC Cancer staging manual: Springer New York; 2010.

14. Petermann D, Demartines $N$ and Schäfer $M$. Is tumour size an underestimated feature in the current TNM system for malignancies of the pancreatic head? HPB 2013;15(11):872-881.

15. Meyer W, Jurowich $C$, Reichel $M$, Steinhäuser $B$, Wünsch $P H$ and Gebhardt C. Pathomorphological and histological prognostic factors in curatively resected ductal adenocarcinoma of the pancreas. Surgery today 2000;30(7):582-587.

16. Kedra B, Popiela T, Sierzega M and Precht A. Prognostic factors of long-term survival after resective procedures for pancreatic cancer. Hepato-Gastroenterol. 2000;48(42):1762-1766.

17. de Jong MC, Li F, Cameron JL, Wolfgang CL, Edil BH, Herman JM, et al. Re-evaluating the impact of tumor size on survival following pancreaticoduodenectomy for pancreatic adenocarcinoma. Journal of surgical oncology 2011;103(7):656-662.

18. Benassai G, Mastrorilli M, Quarto G, Cappiello A, Giani U, Forestieri $P$, et al. Factors influencing survival after resection for ductal adenocarcinoma of the head of the pancreas. Journal of surgical oncology 2000;73(4):212-218.

19. Sohn TA, Yeo CJ, Cameron JL, Koniaris L, Kaushal S, Abrams RA, et al. Resected adenocarcinoma of the pancreas-616 patients: results, outcomes, and prognostic indicators. Journal of gastrointestinal surgery 2000;4(6):567-579.

20. Sperti C, Bonadimani B, Pasquali C, Piccoli A, Cappellazzo F, Rugge M, et al. Ductal adenocarcinoma of the pancreas: clinicopathologic features and survival. Tumori. 1993;79(5):325-330.

21. Yamaguchi K, Mizumoto K, Noshiro H, Sugitani A, Shimizu S, Chijiiwa K, et al. Pancreatic carcinoma: $<$ or $=2 \mathrm{~cm}$ versus $>2 \mathrm{~cm}$ in size. International surgery 1998;84(3):213-219.

22. Ahmad NA, Lewis JD, Ginsberg GG, Haller DG, Morris JB, Williams NN, et al. Long term survival after pancreatic resection for pancreatic adenocarcinoma. The American journal of gastroenterology 2001;96(9):2609-2615.

23. Kuhlmann K, De Castro S, Wesseling J, ten Kate F, Offerhaus G, Busch O, et al. Surgical treatment of pancreatic adenocarcinoma: actual survival and prognostic factors in 343 patients. European Journal of Cancer 2004;40(4):549-558.

24. Agarwal B, Correa $A M$ and Ho L. Survival in pancreatic carcinoma based on tumor size. Pancreas 2008;36(1):e15-e20.

25. Reddy S, Wolfgang CL, Cameron JL, Eckhauser F, Choti MA, Schulick RD, et al. Total pancreatectomy for pancreatic adenocarcinoma: evaluation of morbidity and long-term survival. Annals of surgery 2009;250(2):282-287.

26. Howard TJ, Krug JE, Yu J, Zyromski NJ, Schmidt CM, Jacobson LE, et al. A margin-negative RO resection accomplished with minimal postoperative complications is the surgeon's contribution to long-term survival in pancreatic cancer. Journal of gastrointestinal surgery 2006;10(10):1338-1346.

27. Lewis R, Drebin JA, Callery MP, Fraker D, Kent TS, Gates J, et al. A contemporary analysis of survival for resected pancreatic ductal adenocarcinoma. HPB 2013;15(1):49-60.

28. Bilimoria KY, Talamonti MS, Tomlinson JS, Stewart AK, Winchester DP, Ko CY, et al. Prognostic score predicting survival after resection of pancreatic neuroendocrine tumors: analysis of 3851 patients. Annals of Surgery 2008;247(3):490-500.

29. Hsu H-P, Yang T-M, Hsieh Y-H, Shan Y-S and Lin P-W. Predictors for patterns of failure after pancreaticoduodenectomy in ampullary cancer. Annals of Surgical Oncology. 2007;14(1):50-60.

30. Qureshi A, Hassan U and Azam M. Morphology, TNM staging and survival with pancreatico-duodenectomy specimens received at Shaukat Khanum Memorial Cancer Hospital and Research Centre, Pakistan. Asian Pac J Cancer Prev 2011;12:953-956.

31. Chen JW, Bhandari M, Astill DS, Wilson TG, Kow L, Brooke--Smith $M$, et al. Predicting patient survival after pancreaticoduodenectomy for malignancy: histopathological criteria based on perineural infiltration and lymphovascular invasion. HPB 2010;12(2):101-108.

32. Garcea G, Dennison A, Ong S, Pattenden C, Neal C, Sutton $C$, et al. Tumour characteristics predictive of survival following resection for ductal adenocarcinoma of the head of pancreas. European Journal of Surgical Oncology (EJSO) 2007;33(7):892-897.

33. Rohan VS, Hsu J-T, Liu K-H, Yeh C-N, Yeh T-S, Jan Y-Y, et al. Long-term results and prognostic factors in resected pancreatic body and tail adenocarcinomas. Journal of gastrointestinal cancer 2013;44(1):89-93.

34. Chiang K-C, Yeh C-N, Ueng S-H, Hsu J-T, Yeh T-S, Jan Y-Y, et al. Clinicodemographic aspect of resectable pancreatic cancer and prognostic factors for resectable cancer. World $\mathrm{J}$ Surg Oncol 2012;10(1):77.

35. Magistrelli P, Antinori A, Crucitti A, La Greca A, Masetti R, Coppola R, et al. Prognostic factors after surgical resection for pancreatic carcinoma. Journal of surgical oncology 2000;74(1):36-40.

36. Ueda M, Endo I, Nakashima M, Minami Y, Takeda K, Matsuo K, et al. Prognostic factors after resection of pancreatic cancer. World journal of surgery 2009;33(1):104-110.

37. Shimada K, Sakamoto Y, Sano T and Kosuge T. Prognostic factors after distal pancreatectomy with extended lymphadenectomy for invasive pancreatic adenocarcinoma of the body and tail. Surgery 2006;139(3):288-295.

38. Connor S, Bosonnet L, Ghaneh P, Alexakis N, Hartley M, Campbell $F$, et al. Survival of patients with periampullary carcinoma is predicted by lymph node 8 a but not by lymph node $16 b 1$ status. Br J Surg 2004;91(12):1592-1599.

39. Shoup M, Conlon KC, Klimstra D and Brennan MF. Is extended resection for adenocarcinoma of the body or tail of the pancreas 
justified? Journal of gastrointestinal surgery 2003;7(8):946-952.

40. Lim JE, Chien MW and Earle CC. Prognostic factors following curative resection for pancreatic adenocarcinoma: a populationbased, linked database analysis of 396 patients. Annals of surgery 2003;237(1):74.

41. Takai $S$, Satoi $S$, Toyokawa $H$, Yanagimoto $H$, Sugimoto $N$, Tsuji K, et al. Clinicopathologic evaluation after resection for ductal adenocarcinoma of the pancreas: a retrospective, singleinstitution experience. Pancreas 2003;26(3):243-249.

42. Han S-S, Jang J-Y, Kim S-W, Kim W-H, Lee KU and Park Y-H. Analysis of long-term survivors after surgical resection for pancreatic cancer. Pancreas 2006;32(3):271-275.

43. Li Q, Gao C, Li H, Juzi JT, Chen H and Hao X. Factors associated with survival after surgical resection in Chinese patients with ductal adenocarcinoma of the pancreatic head. Digestive Surgery 2007;25(2):87-92.

44. Pawlik TM, Gleisner AL, Cameron JL, Winter JM, Assumpcao L, Lillemoe KD, et al. Prognostic relevance of lymph node ratio following pancreaticoduodenectomy for pancreatic cancer. Surgery 2007;141(5):610-618.

45. Wells G, Shea B, O'connell D, Peterson J, Welch V, Losos M, et al. The Newcastle-Ottawa Scale (NOS) for assessing the quality of nonrandomised studies in meta-analyses. 2000.

46. Bilimoria KY, Bentrem DJ, Ko CY, Ritchey J, Stewart AK, Winchester DP, et al. Validation of the $6^{\text {th }}$ edition AJCC pancreatic cancer staging system. Cancer. 2007;110(4):738-744.

47. Franko J, Hugec V, Lopes TL and Goldman CD. Survival among pancreaticoduodenectomy patients treated for pancreatic head cancer 1 or $2 \mathrm{~cm}$. Annals of surgical oncology 2013;20(2):357-361.

48. Wagner M, Redaelli C, Lietz M, Seiler C, Friess H and Büchler M. Curative resection is the single most important factor determining outcome in patients with pancreatic adenocarcinoma. $\mathrm{Br} J$ Surg 2004;91(5):586-594.

49. Fortner JG, Klimstra DS, Senie RT and Maclean BJ. Tumor size is the primary prognosticator for pancreatic cancer after regional pancreatectomy. Annals of surgery 1996;223(2):147.

50. Geer RJ and Brennan MF. Prognostic indicators for survival after resection of pancreatic adenocarcinoma. The American journal of surgery 1993;165(1):68-73.

51. Mayo SC, Nathan H, Cameron JL, Olino K, Edil BH, Herman JM, et al. Conditional survival in patients with pancreatic ductal adenocarcinoma resected with curative intent. Cancer 2012;118(10):2674-2681.

52. Yeo CJ, Cameron JL, Sohn TA, Lillemoe KD, Pitt HA, Talamini MA, et al. Six hundred fifty consecutive pancreaticoduodenectomies in the 1990s: pathology, complications, and outcomes. Annals of surgery 1997;226(3):248.

53. Jamieson NB, Denley SM, Logue J, MacKenzie DJ, Foulis AK, Dickson EJ, et al. A prospective comparison of the prognostic value of tumor-and patient-related factors in patients undergoing potentially curative surgery for pancreatic ductal adenocarcinoma. Annals of surgical oncology 2011;18(8):2318-2328.

54. Cameron JL, Crist DW, Sitzmann JV, Hruban RH, Boitnott JK, Seidler AJ, et al. Factors influencing survival after pancreaticoduodenectomy for pancreatic cancer. The American journal of surgery 1991;161(1):120-125.

55. Moon HJ, An JY, Heo JS, Choi SH, Joh JW and Kim YI. Predicting survival after surgical resection for pancreatic ductal adenocarcinoma. Pancreas 2006;32(1):37-43.

56. Böttger T, Zech J, Weber W, Sorger K and Junginger T. Relevant factors in the prognosis of ductal pancreatic carcinoma. Acta chirurgica scandinavica 1989;156(11-12):781-788.

57. Brennan MF, Kattan MW, Klimstra D and Conlon K. Prognostic nomogram for patients undergoing resection for adenocarcinoma of the pancreas. Annals of surgery 2004;240(2):293.

58. Hartwig W, Hackert T, Hinz U, Gluth A, Bergmann F, Strobel O, et al. Pancreatic cancer surgery in the new millennium: better prediction of outcome. Annals of surgery 2011;254(2):311-319.

59. Gangi S, Fletcher J, Nathan MA, Christensen JA, Harmsen WS, Crownhart BS, et al. Time interval between abnormalities seen on CT and the clinical diagnosis of pancreatic cancer: retrospective review of CT scans obtained before diagnosis. American Journal of Roentgenology 2004;182(4):897-903.

60. Agarwal B, Abu-Hamda E, Molke KL, Correa AM and Ho L. Endoscopic ultrasound-guided fine needle aspiration and multidetector spiral CT in the diagnosis of pancreatic cancer. The American journal of gastroenterology 2004;99(5):844-850.

61. Bipat S, Phoa SSS, van Delden OM, Bossuyt PM, Gouma DJ, Laméris JS, et al. Ultrasonography, computed tomography and magnetic resonance imaging for diagnosis and determining resectability of pancreatic adenocarcinoma: a meta-analysis. Journal of computer assisted tomography 2005;29(4):438-445

62. Shin HJC, Lahoti S and Sneige N. Endoscopic ultrasound-uided fine-needle aspiration in 179 cases. Cancer Cytopathology 2002;96(3):174-180.

63. Breslin TM, Hess KR, Harbison DB, Jean ME, Cleary KR, Dackiw AP, et al. Neoadjuvant chemoradiotherapy for adenocarcinoma of the pancreas: treatment variables and survival duration. Annals of surgical oncology 2001;8(2):123-132.

64. Regine WF. Postoperative adjuvant therapy: past, present, and future trial development. Pancreatic Cancer: Springer; 2002. p. $235-242$.

\footnotetext{
Authors Contribution:

AS, AB- Reviewed the literature, manuscript preparation and critical revision of the manuscript; SMB, QY-Collected data and review of literature and helped in preparing first draft of manuscript; AS, WJM, HHJ- Statistically analyzed and interpreted, prepared first draft of manuscript and critical revision of the manuscript; FYL- Concept of study and review of study.

Orcid ID:

Dr. Anuj Shrestha: (1) http://orcid.org/0000-0002-3502-6572

Dr. Attit Baskota: (1) http://orcid.org/0000-0003-4006-3092

Dr. Fu Yu Li: (1) http://orcid.org/0000-0003-2755-2887

Dr. Wen Jie Ma: (1) http://orcid.org/0000-0002-9246-4077

Dr. Qin Yang: (i) http://orcid.org/0000-0003-0582-057X

Dr. Hu Hai Jie: (1) http://orcid.org/0000-0001-8027-6725

Dr. Sunil Man Bijukchhe: (i) http://orcid.org/0000-0002-9125-4588

Sources of support: None, Conflict of Interest: None declared.
} 